\title{
Attaining the Room Comfort by Solar Reflective Paint
}

\author{
${ }^{1}$ Sekar, M., ${ }^{2}$ M. Sakthivel, ${ }^{3}$ S. Satheesh Kumar and ${ }^{3}$ C. Ramesh \\ ${ }^{1}$ Department of Mechanical Engineering, \\ Faculty of Mechanical Engineering, Government College of Technology, Coimbatore, India \\ ${ }^{2}$ Department of Mechanical Engineering, \\ Faculty of Mechanical Engineering, Anna University of Technology, Coimbatore, India \\ ${ }^{3}$ Department of Thermal Engineering, \\ Government College of Technology, Coimbatore, India
}

Received 2012-04-21, Revised 2012-05-27; Accepted 2012-06-18

\begin{abstract}
The objective of this research was to provide the Room comfort by means of Solar Reflective Paint (SRP) on the roof and thereby reducing the consumption of electrical energy. Solar heat diffuses through roof into the room resulting in human discomfort. Human discomfort leads to the usage of electrical energy. Valuable energy has to be conserved. Three different samples of solar reflective paint were collected and their properties were studied. The sample suitable for the research was selected. A standard roof design was selected for analysis. Using the properties of solar reflective paint and the roof design, a model was created and was analyzed by using ANSYS. The temperature of the living room was brought down considerably of about $7^{\circ} \mathrm{C}$ by implementing the solar reflecting paint on the roof top. Power consumption can be drastically reduced by using SRP on industries as well as residential buildings. By using SRP, the usage of Air conditioning units can be minimized thereby keeping the global warming in control.
\end{abstract}

Keywords: Cool Roof, Renewable Energy, Room Comfort, Solar Reflective Paint, Solar Radiation

\section{INTRODUCTION}

In our homes, indoor thermal discomfort has been very challenging and it depends on one or more of the materials used either as ceiling board; rock used as walling materials; wood used in making doors; wood sample used in making roofing support; the roofing sheet itself or combination of all of them. One of the special concerns of the trained builders is to design a building that the indoor environmental condition is thermally tolerable and conducive to the occupants of the building. Besides the wall, the ceiling, the door and the roofing materials, used for flooring and carpeting also generate heat thereby contributing in no small measure to the thermal discomfort of a building.

The ceiling materials are made from different materials with different thermal conductivities, thermal absorptivities, thermal diffusivities and thermal resistivities. Depending on how large or small the value of these thermal properties, a particular ceiling material may be more efficient in terms of thermal insulation than another. Observation in the present competitive world reveals that people that are economically favored usually go for the most costly ceiling materials without any preference to the thermal insulation efficiency of the most sought after ceiling materials. It was based on this premise that this work is designed to investigate the thermal properties and thermal insulation efficiency of the most frequently used ceiling materials and to apply a thermal coating on those roofs thereby arriving the temperature inside the building.

Heat propagated in interior spaces is through roofs and walls and partly through ceiling and ceiling panels by the process of conduction and radiation. To reduce this heat propagation, materials of tolerable thermal response are needed to be used in the ceiling, walling as well as the

Corresponding Author: Sekar, M., Department of Mechanical Engineering, Faculty of Mechanical Engineering, Government College of Technology, Coimbatore, India Tel: +919444218206 
roofing design. Substances with higher thermal diffusivities and lower solar radiation absorptivity have tolerable temperature responses and this makes them to be used as better ceiling and ceiling panels.

Modern urban areas have typically darker surfaces and less vegetation than their surroundings. Collectively, dark surfaces and reduced vegetation warm the air over urban areas, leading to the creation of urban "heat islands". The additional air-conditioning use caused by this urban air temperature increase is responsible for $5-10 \%$ of Indian urban peak electric demand, at a direct cost of several crores annually. Summer heat islands increase system-wide cooling loads and smog production because of higher urban air temperatures.

Smog is created by photochemical reactions of pollutants in the air; and these reactions are more likely to intensify at higher temperatures. Uses of solarreflective paints on urban surfaces are inexpensive measures that can reduce summertime temperatures. At the building scale, a dark roof is heated by the sun and thus directly raises the summertime cooling demand of the building beneath it (Akbari and Levinson, 2009). A reflective roof is typically light in color and absorbs less sunlight than does a conventional dark-colored roof. Thus, reflective roofs reduce air-conditioning $(\mathrm{a} / \mathrm{c})$ energy use and increase occupant comfort level. The magnitude of energy savings depends upon building type, level of roof insulation, ventilation rate between roof and ceiling, $\mathrm{A} / \mathrm{c}$ size and efficiency and of course, roof solar reflectance.

Cool roof technologies include coatings, membranes, tiles and shingles. The primary intent of cool roof technology is to reduce the amount of energy absorbed by a roof surface. New advanced coating materials allow for the selective absorption and reflection of various spectral wavelengths. This allows for the design of roofing systems with visual coloring that can enhance a building's character while still reflecting a good deal of the total incident solar energy, of which a significant portion extends beyond the visual wavebands to include infrared and ultraviolet light. The net result is that a lower fraction of the incident solar energy is absorbed by the structure. This reduces the cooling load on the building's HVAC as well as significantly increases the expected life of the building's roof. The environmental benefits of cool roofs are that they can decrease the urban heat island effect by reflecting some of the incident solar energy back into space as opposed to absorbing the heat and releasing it to the surroundings. Light-colored building surfaces are a time-honored technique of staying cool in the Mediterranean, the Caribbean and other sun-drenched locales. Roofing materials with high reflectance, or high albedo, can reflect up to $85 \%$ of incident solar radiation, compared to normal surfaces which may reflect only $20 \%$. The differences between the conventional and cool roofs were discussed in Table 1.

Increasing the solar reflectance of the urban surface reduces its solar heat gain, lowers its temperatures and decreases its outflow of thermal infrared radiation into the atmosphere. This process of "negative radiative forcing" effectively counters global warming. Most existing flat roofs are dark and reflect only $10-20 \%$ of sunlight. Akbari and Levinson (2009) have shown that resurfacing conventional dark roofs with a cool white material that has a long-term solar reflectance of 0.60 or more increases its solar reflectance by at least 0.40 . Retrofitting $100 \mathrm{~m}^{2}$ of roof has an effect on radiative forcing equivalent to a one-time offset of 10 tonnes of $\mathrm{CO}_{2}$. Given that $\mathrm{CO}_{2}$ is currently traded in Europe at $\$ 20 /$ tonne, the value of this change could be worth up to $\$ 200$.

In addition to reflecting light back into the atmosphere, it is well established that cool roofs reduce energy use in air conditioned buildings and increase comfort in unconditioned buildings. Similarly, the widespread application of cool roofs and cool pavements helps to mitigate summer urban heat islands, thereby reducing the overall air conditioning load and improving outdoor air quality and comfort.

\subsection{Roof Codes and Standards}

In much of the world, the design, construction and materials used for residential and commercial buildings are guided by building codes. Building codes are an obvious leverage point for promoting cool roofs. The bulk of the codes are dedicated to ensuring the integrity of the building from a health and safety perspective, but the codes also cover matters relating to energy use and have, in recent years, become increasingly inclusive of requirements that save energy in buildings as long such measures are cost competitive. Because building codes are focused on the energy savings potential of individual buildings, they do not consider the climate benefits of cool roofs or the microclimate benefits of reducing the heat island effect. As a result, building codes inherently undervalue cool roofs within the suite of efficiency options (e.g., insulation, efficient windows, radiant barriers).

Table 1. Thermal benefits of cool technology

\begin{tabular}{ll}
\hline Conventional roof & Cool roof \\
\hline Reflects 30 to $60 \%$ of & Reflects $80 \%$ of \\
incident solar & incident solar \\
$\begin{array}{l}\text { Absorbs } 40 \text { to } 70 \% \text { of incident } \\
\text { solar-(heats top roof adding to } \\
\text { cooling load and urban heat) }\end{array}$ & Absorbs nearly 20\% \\
\hline
\end{tabular}


The process for updates, degree of centralization and level of enforcement of building codes vary greatly by country. In China, there is a single national code with three climate zones. In India, there is a single national code, but it is voluntary. In the European Union (EU), building codes are decentralized, determined at the country level. The variation in building codes creates a range of different possible strategies for the promotion of cool roofs. Because of large population and significant growth in infra-structure, China and India may present the greatest near-term opportunities for effective promotion of cool roofs through building codes. India particularly offers great promises as its population density, growth in buildings and tropical climate zones make it a high potential region for cool roofs. Further, the Indian government's interest in climate mitigation/adaptation is considerable and the playing field is shifting rapidly towards greater capacity for energy efficiency implementation of all kinds.

The European Union (particularly its southern countries that require significant summertime cooling) also offers significant opportunities. In February 2009, the EU Cool Roof Council (EU-CRC) organized its first meeting to promote and provide support for installation of cool roofs in Europe. Brazil with its large population and mostly hot climate also offers significant opportunities. The "One Degree Less" movement (ODL 2009), pioneered in Brazil, has adopted cool roofs and heat island mitigation as its first practical program to combat global warming. However, in Brazil the lack of building codes can create challenging conditions. Other developed (e.g., Australia) and developing countries in Middle East and Africa offer significant opportunities for installing white roofs to save energy and cool the globe. Many traditional (but ignored) architectural practices use passive technologies (including white roofs and walls) for improving indoor comfort in buildings (Romagnoni and Peron, 2008).

Absorptance and reflectance of building materials are usually measured across the solar spectrum, since they will be exposed to that range of wavelengths and these are the major characteristics responsible for urban heat gain/loss. The emissivity of building materials, on the other hand, is usually measured in the far-infrared part of the spectrum, since most building materials don't get hot enough to radiate at the shorter near-infrared, visible and UV wavelengths (USAID, 2007). Installation of high-albedo roof coatings or paint is most cost-effective if done during new construction or when buildings are scheduled for re-roofing. Reflectance (albedo) is measured on a scale of 0 to 1 , with 0 being a perfect absorber and 1 being a perfect reflector. The complement of reflectance is absorptance; whatever radiant energy incident on a surface that is not reflected is absorbed. Absorptance is also rated from 0 to 1 and can be calculated from the relation: reflectance + absorptance $=1$. An ideal exterior surface coating for a cooling climate would have reflectance near 1.0, absorptance near zero and infrared emissivity near 1.0 to radiate absorbed heat back to the sky Provisions for cool roofs in energy-efficiency standards can promote the building- and climate-appropriate use of cool roofing technologies. Cool-roof requirements are designed to reduce building energy use, while energy-neutral cool-roof credits permit the use of less energy efficient components (e.g., larger windows) in a building that has energy-saving cool roofs. Both types of measures can reduce the life-cycle cost of a building.

Since 1999, several widely used building energy-efficiency standards, including ASHRAE 90.1, ASHRAE 90.2, the International Energy Conservation Code and California's Title 24 have adopted cool-roof credits or requirements. Akbari and Levinson (2009) have summarized these standards. The techniques used to develop the ASHRAE and Title 24 cool roof provisions can be used as models to address cool roofs in building energy-efficiency standards worldwide.

Prescribing the use of cool roofs in building energy-efficiency standards promotes the cost-effective use of cool roofs to save energy, reduce peak power demand and improve air quality. Another option is to credit, rather than prescribe, the use of cool roofs. This can allow more flexibility in building design, permitting the use of less energy-efficient components in a building that has energy-saving cool roofs. Such credits are energy neutral, but may still reduce peak power demand and improve air quality. They may also reduce the first cost of the building.

The following is a list of cool roof standards, building codes, rating and labeling in the U.S (ASHRAE, 2009):

- Ashrae Standard 90.1-2007 prescribes cool materials for low-sloped roofs on nonresidential buildings in some U.S. climates

- Ashrae Standards 90.1-2004 And 90.1-2001 offer credits for cool materials for lowsloped roofs on nonresidential buildings in some U.S. climates

- Ashrae Standard 90.2-2004 offers credits for cool materials for all roofs on residential buildings in some U.S. climate zones

- International Energy Conservation Code allows commercial buildings to comply by satisfying the requirements of ASHRAE Standard 90.1, which at the time that IECC 2003 was written offered cool-roof credits 
- Chicago, Il Energy Conservation Code prescribes a minimum solar reflectance and thermal emittance for low-sloped roofs

- Florida Building Code prescribes cool materials for all roofs on non residential buildings that are essentially the same as those in ASHRAE Standard 90.1-2004

- U.s. Epa energy starTM label currently requires that low-slopedroofing products have initial and three-year-aged solar reflectances not less than 0.65 and 0.50 , respectively. Steep-sloped roofing products must have initial and three-year-aged solar reflectances not less than 0.25 and 0.15 , respectively

\section{MATERIALS AND METHODS}

\subsection{Solar Reflective Paint}

SRP differ from other method of insulation because of its unique formula. Solar Reflective Paint (SRP) provides a durable thermal barrier. The insulating hollow ceramic beads incorporated in the SRP formula behave much like glass however even more efficient.

SRP dissipates heat. The hollow ceramic microspores reflective quality affects the warming phenomenon called "Mean radiant Temperature" where heat waves from a source such as direct sunlight cause a person to fell warmer even though the actual air temperature is no different between a shady and sunny location. It is molecular friction within the skin, which makes the body feel warmer. So the surrounding air can be cooler but the body will feel warmer in the presence of SRP, meaning thermostats can be set lower for the same degree of comfort.

Ceramic is a poor conductor of heat and is more effective than the bulky materials generally used for this purpose. The SRP roof system is unsurpassed in its ability to dissipate heat. It reflects most solar energy so it never gets into the structure to become a heat problem. There is no heat storage build up as with bulk insulation. The high performance thermal coating also prevents roof expansion and contraction. This drastically reduces the possibility of roof leakages caused by thermal shock and reduces malignance costs accordingly.

\subsection{Hollow Hemispherical Spheres}

SRP's unique Ceramic insulation was made available with the discovery by NASA proving that a thin layer of ceramics as used on the Space Shuttle protects the astronauts from the fiery inferno encountered upon re-entry into the earth's atmosphere SRP integrates a blend of ceramic borosilicate (microscopic hollow glass beads) and various ceramic fillers that when combined form a true ceramic insulator. When applied to a wall surface at 25 mils dry film thickness, it can produce an insulation equivalent of up to R-17 (4 inches of foam insulation). When this insulation equivalent is combined with the reflectance properties in SRP, the comparable R-Value may be as high as R-24. R-Value is directly relative to dry film thickness and the type of surface to which the coating is applied. SRP's Ceramic Insulating qualities create a shield of millions of hollow ceramic microspheres. Ceramics are very poor conductors of heat and therefore become effective as an insulator. Figure 1 shows the Hollow hemispherical sphere in SRP. The ceramics in SRP refract, dissipate and reflect heat to reduce the damaging effects of moisture and condensation. Ceramics are formed by the excessive heating and firing of mostly nonmetallic substances that when formed will virtually dissipate 2,000 degrees of heat. SRP uses this unique technology to provide superior insulation.

\subsection{Solar Reflective Paint Benefits}

- SRP swells when wet becoming waterproof. Breathes when atmosphere is dry. So trapped moisture can escape. This prevents blistering

- Elastomeric, seal cracks and prevent new ones from developing

- Washable

- Waterproofing the roofing will withstand the ponding of water

- Has an insulative equivalent to an R-22 insulation against solar heat

- Mildew and fungus resistant

- High resistance to atmospheric pollution

- Chemical resistance

- Reduce noise

- Dissipates heat

- Cost effective will pay for itself in a short time by energy savings

- Great adhesion to most surfaces

- Reduces thermal shock

- Exceptional elongation characteristics

- Works on very hot surfaces

- UV protection

- Dirt resistant

\subsection{Cost and Energy Savings}

SRP decrease the amount of air conditioning needed to cool a home or building reducing energy use and monthly cooling bills. 


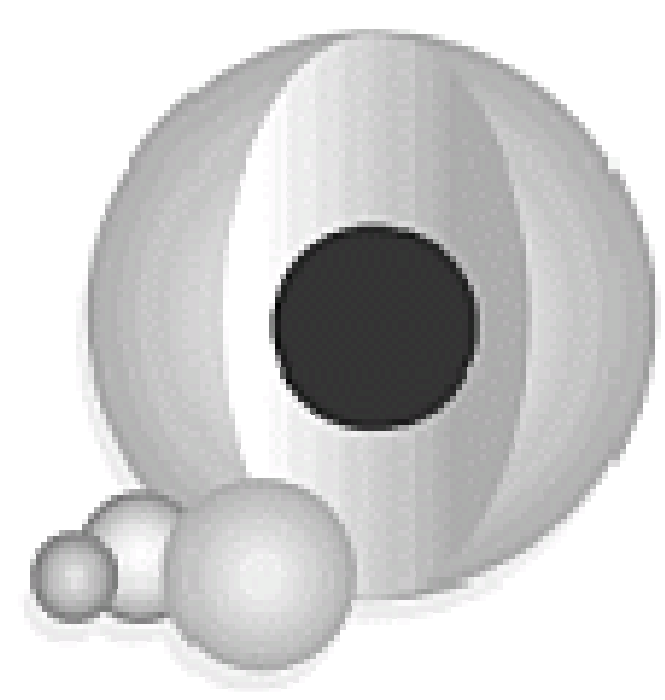

Fig. 1. Hollow hemisherical spheres

\subsection{Downsized A/C Equipment}

SRP roof can reduce peak cooling demand by $15-20 \%$. As result the home or industry owner may be able to purchase a smaller more efficient and less-expensive cooling system.

\subsection{Lowered Surrounding Temperature}

As much as more homes and industries install SRP roofs, the overall surrounding air temperature and cooling demand of the community will decrease.

\subsection{Decreased Pollution in Urban Areas}

Roofs without thermal coating cause the temperature of the air passing over them to rise resulting in an increase in the overall temperature leads to increased building and vehicle air-conditioning demand resulting in increased levels of smog and the associated increased incidence of heat and smog-related health problems. SRP roof lowers the surrounding air temperature and decrease necessary cooling demands and they reduce the amount of smog in the air and benefit the entire community.

\subsection{Waterproofing Control}

SRP has excellent elongation and recovery properties. The hollow ceramic micro spheres used in SRP are over $60 \%$ voids. They are bonded directly to the surface forming a seamless blanket. This prevents warm air to cold surface contact reduces the temperature differential thereby reducing or eliminating condensation.

\subsection{Thermal Control}

SRP is a superior insulating material. Key among the advance features of SRP is the placement of hollow ceramic micro-sphere as a component specially formulated with acrylic materials that keeps the borosilicate ceramic spheres in uniform suspension. Surfaces that are coated with SRP are reluctant to conduct heat and refract as well as dissipate heat away from the surface. Since it is fluid applied, it forms as seamless monolithic seal, eliminating virtually all air infiltration that can be a major source of heat transfer in buildings. SRP can be sprayed or rolled on to form a seamless monolithic seal over any size or shape of roof. The SRP roof system effectively dissipates and reflects solar radiation back into the atmosphere, resulting in an impressive reduction in solar loading. The SRP roof systems can be applied directly to most clean dry sound substrates including metal.

The hollow glass micro spheres in SRP are pure sodium borosilicate and are less than 100 microns in diameter. Each closed cell acts as an efficient insulator. Once applied water evaporates from the SRP aqueous acrylic emulsion and the hollow ceramic spheres approach each other eventually touch fusing into a continuous membrane.

\subsection{Variable Permeability}

The polymers used in the SRP roof systems expand when wet, offering unparalleled protection expands when wet offering unparalleled protection against damaging moisture penetration. The polymers shrink when dry, allowing any trapped moisture build up to safety escape to the atmosphere, thus helping prevent blistering.

\subsection{SRP Resins} benefits:

Acrylic elastomeric resins add the following

- They remain elastic-move with changes in the building covering cracks and preventing new ones from appearing

- They cover the entire surface with a seamless membrane preventing water or air penetration

- They give UV protection. They get tougher and stretchier with UV exposure, insuring long life

The roof coat resin has a very special property known as "Variable Permeability". When conditions are wet, the polymers swell up becoming completely watertight. When conditions are dry, the pores in the roof coat open up and trapped moisture can breathe out. Other roofing products are watertight all the time. 
Sekar, M. et al. / American Journal of Environmental Science 8 (5) (2012) 556-562

Table 2. SRP Properties

\begin{tabular}{|c|c|c|c|c|c|c|}
\hline $\begin{array}{l}\text { Coating } \\
\text { thickness (m) }\end{array}$ & Pern & $\begin{array}{l}\text { Thermal } \\
\text { conductivity } \\
(\mathrm{w} / \mathrm{mk})\end{array}$ & $\begin{array}{l}\text { Solar } \\
\text { emittance } \\
(\%)\end{array}$ & $\begin{array}{l}\text { Solar } \\
\text { reflectance } \\
(\%)\end{array}$ & $\begin{array}{l}\text { Overall heat } \\
\text { transfer coefficient } \\
\left(\mathrm{w} / \mathrm{m}^{2} \mathrm{k}\right)(\mathrm{U})\end{array}$ & $\begin{array}{l}\text { Adhession } \\
\text { strength }\end{array}$ \\
\hline 400 & 8.8 & 0.0515 & 94 & 86 & 30 & 0.90 \\
\hline
\end{tabular}

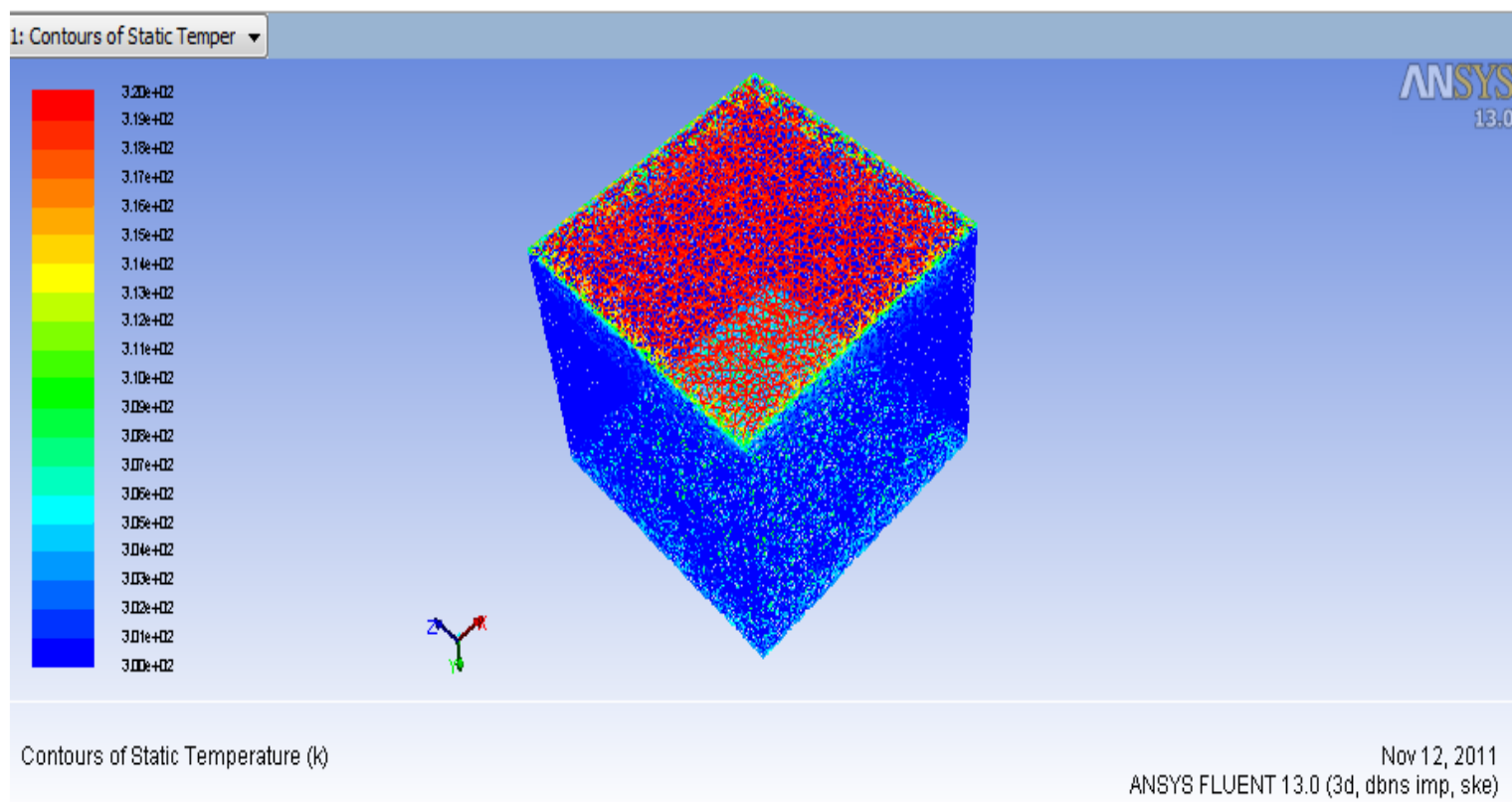

Fig. 2. Meshing of living room

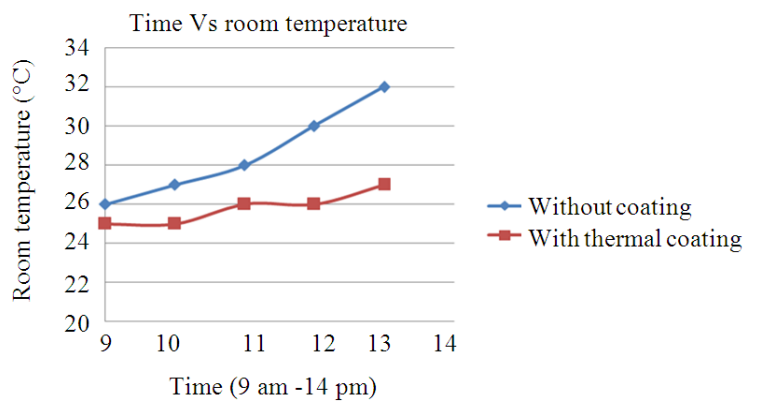

Fig. 3. Comparison of room temperature

Moisture will work up through the substrata and become trapped under the waterproof material. When this heats up it turns water to vapor expanding many times causing blistering and destroying adhesion or it freezes which than also breaks down the adhesion, leading to roof failure.

SRP uses ceramic micro-spheres very similar to the ceramics used in the space shuttles, which are close to indestructible by the conditions faced each day by buildings. Ceramic micro-spheres are about $50 \%$ by volume in SRP. The micro-spheres help thermal coating to reflect about $83 \%$ of sunlight. They stop most radiant heat transfer before it ever becomes a problem. Ceramics is one of the best non-conductors of heat. Other type of insulation just slows down the transfer of heat. Ceramic can dissipate heat, transferring it back into the atmosphere. The heat never gets into the building. Ceramics makes the heat dissipate more quickly from the surface. Because of the ceramic, SRP are more resistant to dirt accumulation. The ceramic micro-spheres themselves are fireproof and can dissipate great amounts of heat. As the result, SRP have good fire resistant properties. Pigment SRP makes use of Titanium dioxide and Aluminium-trihydrate as white pigments. These are very stable substances that are very resistant to natural breakdown. The CFD simulation was conducted using FLUENT software. The basic CFD model of a room as quoted from ASHRAE standard and the boundary and initial conditions are adopted from the experimental environment (Al-Kayiem et al., 2010). Table 2 shows the Properties of Solar Reflective Paint. 


\section{RESULTS}

\subsection{Simulation using FLUENT}

A 3D Model of $25 \mathrm{~m}^{2}$ (Air conditioned room) was developed using Ansys 13. All the parameters such as physical properties of air, thermal properties of roof material, solar reflective paint and the insulation below roof were taken into consideration. Solar radiation was taken into account by inputting the latitude, longitude and elevation of the location selected. The model was subjected to 2500 iterations for achieving the optimum result.

\section{DISCUSSION}

The temperature of the living room was brought down considerably after thermal coating (Romagnoni and Peron, 2008). Nearly $7^{\circ} \mathrm{C}$ difference was achieved by means of Solar reflective paint. Figure 3 show the temperature difference between the living room with thermal coating and the room without thermal coating. From the Fig. 2, it is obvious that the roof that was coated with solar reflective paint reflects sunlight better than that of the ordinary roof.

\section{CONCLUSION}

This study deals with the simulation thermal coating for providing the room comfort and thereby reducing the usage of Air conditioning units and fans. Several input parameters were taken into consideration as per ASHRAE standards. As a result of applying the SRP technology, the temperature of the living room was brought down considerably. This technology can widely be applied in industrial sectors to reduce the room comfort costs. Apart from reducing the temperature of the living room, SRP helps in keeping the environment free from pollution and global warming.

\section{REFERENCES}

Akbari, H. and R. Levinson, 2009. Global cooling: Policies to cool the world and offset global warming from $\mathrm{CO}_{2}$ using reflective roofs and pavements. Proceedings of the 2nd International Conference on Countermeasures to Urban Heat Islands, Sept. 21-23, Heat Island Publications, Berkeley, CA.

Al-Kayiem, H.H., M.F.B.M. Sidik and Y.R.A.L. Munusammy, 2010. Study on the thermal accumulation and distribution inside a parked car cabin. Am. J. Applied Sci., 7: 784-789. DOI: 10.3844/ajassp.2010.784.789

ASHRAE, 2009. Most of the principles and guidelines necessary to understand the ASHRAE Standards. ASHRAE Handbook Fundamentals.

Romagnoni, P. and F. Peron, 2008. Impact of Solar radiation on the temperature of thermal insulation materials in roof applications. Architecture University Institute of Venice.

USAID, 2007. An Introduction to cool roof. IRG. 